\title{
Synergistic disruptions in seuss cyp85A2 double mutants reveal a role for brassinolide synthesis during gynoecium and ovule development
}

\author{
Staci Nole-Wilson ${ }^{\dagger}$, Elizabeth E Rueschhoff ${ }^{\dagger}$, Huda Bhatti, Robert G Franks
}

\begin{abstract}
Background: The Arabidopsis SEUSS (SEU) gene encodes a transcriptional adaptor protein that is required for a diverse set of developmental events, including floral organ identity specification, as well as gynoecium, ovule and embryo development. In order to better understand the molecular mechanisms of SEUSS action we undertook a genetic modifier screen to identify seuss-modifier (sum) mutations.

Results: Screening of M2 lines representing approximately 5,000 M1 individuals identified mutations that enhance the seuss mutant phenotypic disruptions in ovules and gynoecia; here we describe the phenotype of the sum63 mutant and enhanced disruptions of ovule and gynoecial development in the seu sum63 double mutant. Mapping and genetic complementation tests indicate that sum63 is allelic to CYP85A2 (AT3G30180) a cytochrome p450 enzyme that catalyzes the final steps in the synthesis of the phytohormone brassinolide.

Conclusions: Our identification of mutations in CYP85A2 as enhancers of the seuss mutant phenotype suggests a previously unrecognized role for brassinolide synthesis in gynoecial and ovule outer integument development. The work also suggests that seuss mutants may be more sensitive to the loss or reduction of brassinolide synthesis than are wild type plants.
\end{abstract}

\section{Background}

SEUSS (SEU) is a member of a family of transcriptional co-regulators that controls a diversity of developmental events in Arabidopsis thaliana [1,2]. SEU is required for repression of $A G A M O U S$ during floral organ identity specification. The SEU protein has been shown to physically interact with members of the MADS domain homeobox transcription factor family as well as other transcriptional co-regulators (LEUNIG (LUG) and LEUNIG_HOMOLOGUE [3-6]). These protein interactions mediate repression of $A G$ transcription through the recruitment of a histone deacetylase protein, as well as components of the mediator complex [4,5,7]. These data taken together support a model in which SEU functions as a bridging protein that enables the recruitment of LUG and associated histone deacetylase activities by DNA binding proteins of the MADS domain family. In

\footnotetext{
* Correspondence: rgfranks@ncsu.edu

+ Contributed equally

Department of Genetics, North Carolina State University, Raleigh NC. 27695
} USA

(c) 2010 Nole-Wilson et al; licensee BioMed Central Ltd. This is an Open Access article distributed under the terms of the Creative Commons Attribution License (http://creativecommons.org/licenses/by/2.0), which permits unrestricted use, distribution, and reproduction in any medium, provided the original work is properly cited. this model $S E U$ is required for repression of $A G$ in floral whorls that will give rise to perianth organs where these protein complexes are most active [5].

$S E U$ and $L U G$ are also required for development of the medial domain of the gynoecium [8,9]. The medial domain of the Arabidopsis gynoecium contains the carpel margin meristem, a vital meristem that gives rise to the ovules and other tissues required for female reproductive competence. The effect of seu or lug single mutants on medial domain development is relatively mild, however both seu and lug single mutants display a dramatic synergistic interaction with aintegumenta (ant) mutants. In seu ant or lug ant double mutants development of the gynoecial medial domain is greatly disrupted resulting in the loss of ovule primordia. These results suggest that $S E U$ and $L U G$ participate with $A N T$ in gene regulation events that are required for the development of the medial gynoecial domain.

$A N T$ encodes a DNA binding transcription factor of the AP2 gene family that functions during organogenesis $[10,11]$. ANT potentiates organ growth by engendering a 
competence for cellular divisions during organ development $[12,13]$. The ant single mutants display fewer and smaller lateral organs in both vegetative and reproductive parts of the plant as well as alterations in the development of the ovule integuments $[10,11]$. The integuments are layers of cells that later form into the seed coat. In the ant single mutant both the inner and outer integuments fail to develop properly. SEU and $L U G$ also play a role in the development of the ovule integuments $[1,14]$. However, the seu and $l u g$ single mutants display a relatively mild disruption of ovule integument development that is incompletely penetrant.

Brassinosteroid hormones are a class of plant hormones that play a role in a wide variety of developmental processes $[15,16]$. The two main active brassinosteriod hormones in Arabidopsis are castasterone (CS) and brassinolide (BL). The synthesis of these two hormones in Arabidopsis requires a cytochrome p450 (cyp450)-type enzyme, CYP85A2 (At3G30180) that is rate-limiting for the conversion of 6-deoxyCS to CS and CS to BL $[17,18]$. However, the phenotype of the cyp $85 A 2$ mutant is much less severe than that of the brassinosteroid insensitive bri1 mutant [19]. This is due in part to the partially redundant activity of a paralogous cytochrome p450 enzyme, CYP85A1 (At5G38970) and by the presence of CYP85Aindependant pathways for the production of CS $[17,18]$.

Here we report synergistic genetic interactions between mutations in the CYP85A2 gene and seu mutants that affect the development of the gynoecial medial domain and the development of the ovule outer integument. We identified a cyp85A2 mutant allele, termed seuss-modifier 63 (sum63), in a screen for genetic enhancers of the seu gynoecial phenotype. Mapbased cloning efforts and complementation tests demonstrated that sum63 is allelic with existing cyp85A2 alleles. The seu cyp $85 A 2$ double mutants generated in either a Col-0 or Ler background displayed enhanced disruptions of gynoecial and ovule development. Our results highlight a previously undocumented sensitivity of the seu mutants to the reductions in the activity of the brassinosteriod synthesis pathway. This work also points to a role for brassinosteriod hormones in ovule outer integument and gynoecial medial domain development.

\section{Results and Discussion}

The seu-1 mutant allele conditions a weak organ identity transformation phenotype that results from the ectopic expression of $A G$ [1]. The seu-1 mutant also conditions slight splitting of the gynoecial tube and a partially penetrant ovule outer integument defect (Figure 1 and 2). The gynoecial and ovule defects of the seu-1 single mutant result in a slight reduction in seed set and gynoecial length (Table 1 and data not shown). We mutagenized seu- 1 seeds and visually screened the M2 generation for second site mutations that enhanced the sterility and gynoecial splitting of the seu-1 mutant (Methods). We uncovered eleven seuss-modifier (sum) mutations that enhanced the seu-1 phenotype. We focused our initial efforts on sum63 as it showed a synergistic genetic interaction with seu with respect to gynoecial development and female fertility.

\section{Molecular identification and phenotypic analysis of sum63 single mutants}

In order to better characterize the sum63 single mutant phenotype in a wild type background, the seu sum 63 double mutant identified in the screen was backcrossed to the Ler parental ecotype three times and sum63 single mutant lines were isolated. The sum63 single mutants conditioned a moderate reduction in plant height as well as alterations in rosette leaf development (Figure 1M; Table 1). Rosette leaves of the sum63 single mutant were darker green and rounder in shape when compared to wild type leaves. The morphology of the sum63 flower was similar to wild type except that the stamens were shorter than wild type (Figure 1D). This resulted in a slightly reduced ability of the sum63 flower to self fertilize.

We also generated a F2 mapping population by crossing the seu sum63 double mutant (Ler ecotype) to wild type Col-0 plants. The sum63 mutation was rough mapped to an interval of chromosome III between ciw11 and T32N15.42 that included the CYP85A2 (AT3G30180) gene. Comparison of the sum63 single mutant phenotype to the published phenotype for lossof-function alleles of CYP85A2 suggested that sum63 might be allelic with CYP85A2 $[17,18]$. We compared the sequence of the CYP85A2 genomic DNA from Ler and sum63 individuals in an effort to identify the sequence alteration underlying the sum 63 allele. We successfully amplified and sequenced the first 1274 nucleotides of the CYP85A2 gene sequence (transcriptional start site as +1 ) as well as a $3^{\prime}$ portion of the CYP85A2 gene from position +2427 into the 3 'untranslated region (See Table 2 for primer sequences). We found no changes in the sequence of these regions in the sum63 mutant relative to the sequences we derived from Ler DNA. However, we were unable to amplify the intervening portions of the CYP85A2 gene from the sum63 mutants, while these same regions were successfully amplified from Ler individuals. Furthermore, oligonucleotide primers that spanned the intermediate region (i.e. between +1274 and +2427 ) also failed to generate amplicons from the sum63 genomic DNA. These results suggested the presence of a genomic rearrangement in sum63 individuals that disrupts the CYP85A2 gene sequence. Complementation tests between the sum63 


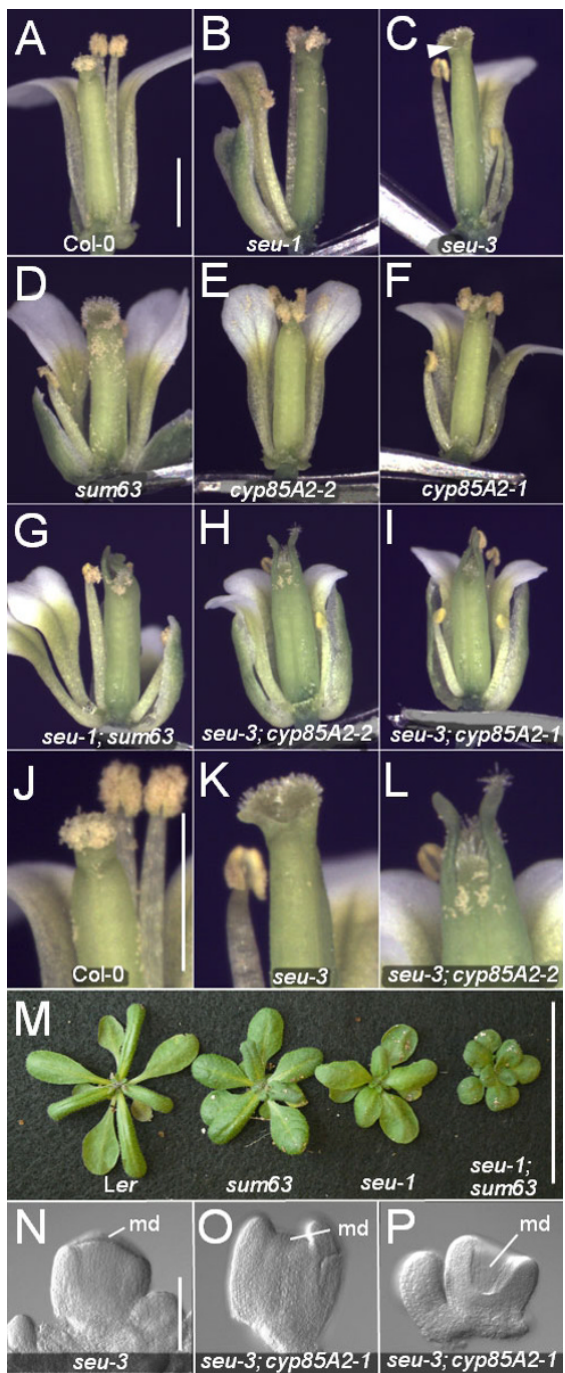

Figure 1 The seu cyp85A2 double mutants condition enhanced gynoecial defects. Photomicrographs of indicated genotypes: panels A-L, flowers where some sepals and petals have been removed to allow viewing of gynoecia; panel $M$, rosette morphology. A) Col-0 wild type flower. B) seu-1 mutant flower. C) seu-3 mutant flower. Note slight split at gynoecial apex (arrowhead). D) sum63 single mutant flower. E) cyp85A2-2 mutant flower. F) cyp85A2-1. Gynoecium splitting is not detected in D-F. G) seu-1 sum63 double mutant. H) seu-3 cyp85A2-2 double mutant. I) seu-3 cyp85A2-1 double mutant. Enhanced splitting at the gynoecial apex is detected in the seu cyp85A2 double mutants relative to the respective single mutants. $J$-L) higher magnification of gynoecial apices shown in $\mathrm{A}, \mathrm{C}$ and $\mathrm{H}$, respectively. M) Rosette phenotypes. $\mathrm{N}$ P) Nomarski optical images of chloral hydrate cleared stage 7 or early stage 8 gynoecia. N) In seu-3 the medial domain (md) extends to apex of gynoecium. At this stage the seu-3 mutant gynoecium shown is indistinguishable from wild type (not shown). O) In the seu-3 cyp85A2-1 double mutant the extent of the medial domain is reduced. P) Severely effected seu-3 cyp85A2-1 gynoecium. Adaxial portions of the medial domain are very reduced resulting in a "hollowed out" gynoecium. Scale bars in A is $1 \mathrm{~mm}$ for panels A-l; scale bar in $J$ is $1 \mathrm{~mm}$ for images $J$-L; scale bar in $M$ is $5 \mathrm{~cm}$; scale bar in $\mathrm{N}$ is $0.1 \mathrm{~mm}$ for $\mathrm{N}-\mathrm{P}$. allele and the previously characterized cyp85A2-1 and cyp85A2-2 alleles $[18,20]$ revealed that sum63 was allelic with these cyp85A2 alleles (data not shown). Thus we have renamed the sum63 allele cyp85A2-4 (Table 3). Characterization of the T-DNA insertion sites in cyp85A2-1 and cyp85A2-2 individuals confirmed disruption of this gene in these lines (Methods). The cyp85A21 allele has been previously reported as a null allele based on a failure to detect transcript in RT PCR assays [17]. The phenotypes of the cyp85A2-1, cyp85A2-2 and cyp85A2-4 alleles are similar suggesting that they are all strong loss-of-function alleles (Figure 1).

\section{The seu cyp85A2 double mutant conditions enhanced disruptions of gynoecial and ovule development}

To further characterize the seu cyp $85 A 2$ double mutant phenotype we created and analyzed the following double mutants: seu-3 cyp85A2-1, seu-3 cyp85A2-2 (both in the Col-0 background) and seu-1 cyp85A2-4 (Ler background). We did not detect an enhancement of the homeotic transformations previously reported for the seu-1 allele [1] in the seu cyp85A2 double mutants. However, all three seu cyp85A2 double mutant combinations displayed enhanced defects in ovule and gynoecial development. Double mutants conditioned enhanced splitting of the apex of the gynoecium relative to the single mutants (Figure 1). The cyp $85 \mathrm{~A} 2$ single mutants did not display splitting of the gynoecial apex and splitting in the seu single mutant was mild and rarely observed in the early arising flowers. In contrast, the gynoecial apex in the seu cyp85A2 double mutants was nearly always split and extended horn like protrusions of the valves were observed. The splitting of the apex and the horn-like protrusions may be the result of a reduction in the growth of the medial domain of the gynoecium. Analysis of earlier stage gynoecia indicate that even as early as floral stage 7 or 8 [21] the medial domain of the gynoecium appears retarded in its growth relative to the lateral or valve domains (Figure $1 \mathrm{~N}-\mathrm{P}$ ). The seu cyp $85 A 2$ double mutants also display a significant reduction in the number of ovule primordia initiated relative to wild type and either single mutant (Table 1). Kim et al. have previously reported that over-expression of CYP85A2 conditions an increased number of seeds per silique, further suggesting a role for CYP85A2 in the development of ovules from the gynoecial medial domain [17].

The seu cyp $85 A 2$ double mutants also conditioned an extreme loss of fertility as these double mutants did not generate viable seeds upon self-fertilization. Our analysis of ovule defects indicated the ovule developmental defects of the double mutant were enhanced relative to either single mutant. The double mutant ovules displayed a reduced growth of the outer integument relative to either single mutant (Figs. 2 and 3). In severe cases the outer integument failed to develop, resulting 


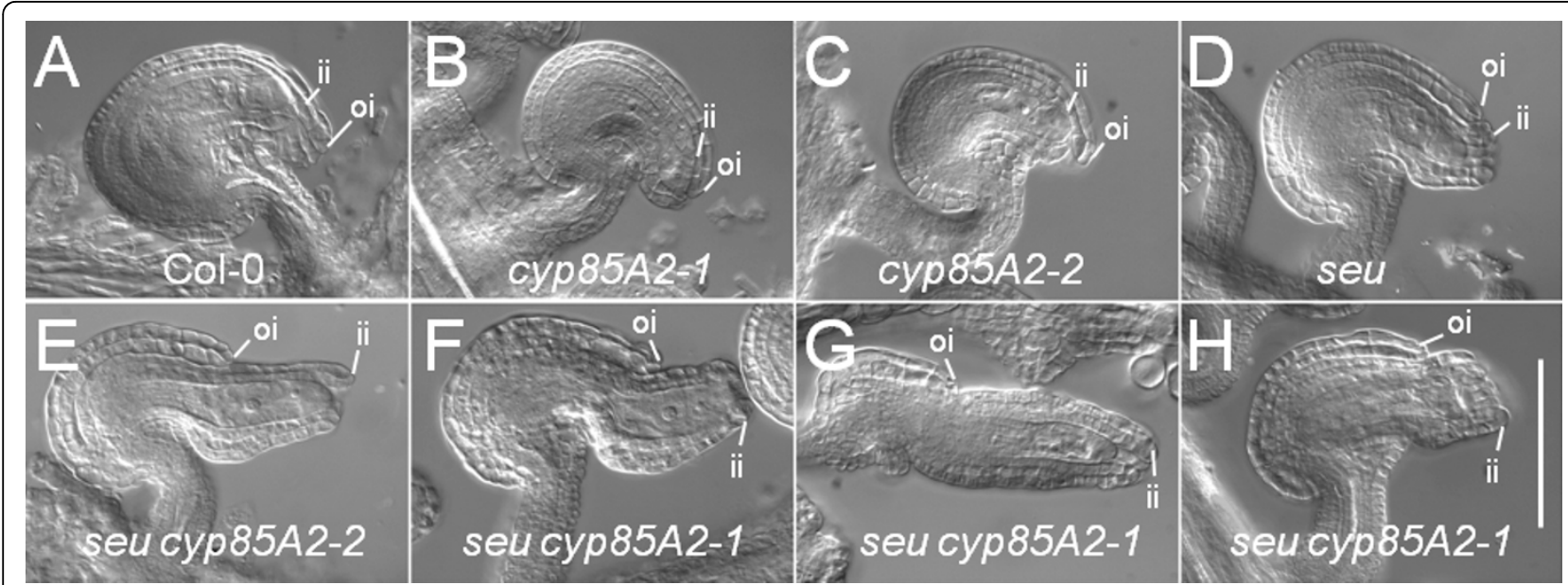

Figure 2 The seu cyp85A2 double mutants condition enhanced outer integument defects. Photomicrograph (Nomarski optics) of chloral hydrate cleared ovules of the indicated genotypes. Extent of inner (ii) and outer (oi) integument growth is indicated. A) Col-0 wild type. B and C) cyp85A2-1 and cyp85A2-2 ovules display near wild type morphology. D) seu-3 single mutant displays slightly reduced growth of outer integument. E) seu cyp85A2-2 ovule. Disruption of outer integument development is greater in the double mutant relative to wild type or either single mutant. F-H) Three examples of seu cyp85A2-1 double mutants display varying degrees of outer integument disruption, but are consistently more disrupted than the wild type or single mutants. Scale bar in $\mathrm{H}$ is 100 microns for all panels.

in a somewhat orthotropic ovule morphology (Figure $2 \mathrm{G})$. Although brassinolide has not previously been reported to play a role in outer integument development, the double mutant phenotype suggests a requirement for the cyp85A2 gene for outer integument development in the seu mutant background. It is likely that the loss of $S E U$ sensitizes the ovule to disruptions in the levels of brassinolide.

We also noted defects in the development of the female gametophytes within the seu cyp $85 \mathrm{~A} 2$ ovules (Figure 3). Often the female gametophyte was missing or failed to reach a mature morphology with a recognizable set of gametophyte cells. As we did not observe segregation distortion with these alleles, it is most likely that the defects in female gametophyte development are an indirect result of the development of the sporophytic tissue of the ovule and not due to a requirement for SEU and CYP85A2 activity in the female gametophyte directly.
Levels of CYP85A2 transcript are reduced in seuss mutant inflorescence samples

We examined the steady state levels of transcript accumulation for the CYP85A2 and SEU transcripts in wt (Col-0), seu-3 and cyp85A2-1 mutant inflorescences. In the seu-3 mutant tissue the level of the CYP85A2 transcript was significantly less ( $41 \%$ of wild type) than that detected in wild type inflorescence samples (Table 4). These data suggest that SEU activity may be required for wild type levels of CYP85A2 transcript accumulation in the inflorescence. No statistically significant difference in the expression of $S E U$ transcript was detected between the wild type and the cyp $85 A 2$ inflorescences tested. Thus CYP85A2 does not appear to be required for expression of the SEU transcript. The cyp85A2-1 allele has been previously reported as a null allele, yet we detected a low level of expression of the CYP85A2 transcript in the cyp85A2-1 inflorescences. However, the cyp85A2-1 allele is still likely a null or near null allele

Table 1 Quantitative phenotypic analysis of cyp85A2 seu double mutants

\begin{tabular}{|c|c|c|c|c|c|c|c|c|c|c|}
\hline & Ler & seu-1 & sum63 & $\begin{array}{l}\text { seu-1; } \\
\text { sum63 }\end{array}$ & Col-0 & seu-3 & сур85A2-1 & сур85A2-2 & $\begin{array}{c}\text { seu-3; } \\
\text { сур85A2-1 }\end{array}$ & $\begin{array}{c}\text { seu-3; } \\
\text { cyp85A2-2 }\end{array}$ \\
\hline plant height (cm) & $\begin{array}{c}12.8 \\
+/-0.71\end{array}$ & $\begin{aligned} & 8.7^{a} \\
+/- & 0.54\end{aligned}$ & $\begin{array}{c}9.1^{a} \\
+/-0.52\end{array}$ & $\begin{aligned} & 4.4^{b} \\
+ & -0.24\end{aligned}$ & $\begin{array}{c}14 \\
+/-0.62\end{array}$ & $\begin{array}{c}9.4^{c} \\
+/-0.68\end{array}$ & $\begin{array}{c}11^{c} \\
+/-0.57\end{array}$ & $\begin{array}{c}10^{c} \\
+/-0.54\end{array}$ & $\begin{array}{c}6.8^{c} \\
+/-0.38\end{array}$ & N.D. \\
\hline ovule number per silique & N.D. & N.D & N.D & N.D & $\begin{array}{c}53 \\
+/-2.0\end{array}$ & $\begin{array}{c}49 \\
+/-1.4\end{array}$ & $\begin{array}{c}45^{c} \\
+/-1.3\end{array}$ & $\begin{aligned} & 45^{c} \\
+ & -1.6\end{aligned}$ & $\begin{array}{l}31^{d} \\
+/-1.1\end{array}$ & $\begin{array}{l}32^{d} \\
+/-1.3\end{array}$ \\
\hline
\end{tabular}

\footnotetext{
${ }^{b}$ indicates statistically different from Ler, seu-1 and sum63

c indicates statistically different from Col-0

${ }^{d}$ indicates statistically different from Col-0, seu-3, cyp85A2-1 and cyp85A2-2

+/- indicates standard error of the mean

N.D. - not determined
}

${ }^{a}$ indicates statistically different from Ler (ANOVA and pair wise Tukey-Kramer HSD; alpha less than 0.05) 
Table 2 Sequences of primers used for amplification and sequencing of the CYP85A2 gene

\begin{tabular}{ll}
\hline primer name & sequence \\
\hline AT3G30180-F1 & TAAACAACGCCACACACACC \\
\hline AT3G30180-613R & CAACGAGCCTCTCATTAGCC \\
\hline AT3G30180-445F & TGGTTGCCCAACAATAGTCTC \\
\hline AT3G30180-1274R & TCCCACAACAAGCTTGAAAA \\
\hline AT3G30180-2427F & TTTGGTGCTCTTGTGTTTTG \\
\hline AT3G30180-3UTRR & CATTGCAAGTAGGCCCAAAT \\
\hline AT3G30180-2938R & TTCCATTTTCTTCTTCTCTCTTTCTC \\
\hline
\end{tabular}

based on the site of the T-DNA insertion that is expected to truncate the CYP85A2 protein product after just 45 amino acids. Thus it seems unlikely that the synergistic enhancement of the seu cyp $85 A 2$ double mutants is entirely conditioned by a seu-mutant dependant reduction of CYP85A2 transcript.

We propose that additional genes are misregulated in the seu mutant background and that these disrupted gene regulation events contribute to the phenotypic enhancement. We speculate that these genes might lie in the brassinosteroid synthesis pathway or might lie in parallel pathways that support common cellular responses (e.g. cell division or cell expansion) in the ovule or the gynoecial medial domain. SEU is required for proper response to the phytohormone auxin and altered auxin signaling may in part condition the disruption of gynoecium medial domain development seen in seu ant double mutants [2,22]. Given the extensive overlap of brassinosteroid-responsive and auxin-responsive genes and the documented requirement of brassinosteroids for transcriptional responses to auxin [23-28], it is possible that the enhanced seu cyp $85 \mathrm{~A} 2$ double mutant phenotypes result from the combined weakening of brassinosteroidand auxin-dependant signaling pathways.

\section{Conclusions}

Our screen for second site genetic modifiers of the seu mutant gynoecial and ovule phenotypes has identified cyp $85 A 2$ as a genetic enhancer of the seu mutant. These results suggest that brassinolide hormones play a previously unappreciated role in the development of the outer integument of the ovule and the gynoecial medial domain. They also suggest that loss of $S E U$ activity may sensitize ovule and gynoecial development to the loss of brassinosteroid hormones. The seu mutant background thus may represent a sensitized genetic background to identify additional regulators of gynoecial and ovule function.

\section{Methods}

\section{Microscopic and morphometric analysis}

For chloral hydrate clearing inflorescences were fixed in ethanol:acetic acid (9:1) for two hours at room temperature, washed in $90 \%$ ethanol (two times) and then cleared overnight at room temperature in either chloral hydrate (Sigma) (2.5 g dissolved in $1 \mathrm{ml}$ of $30 \%$ glycerol) or Hoyer's solution (70\% chloral hydrate, $4 \%$ glycerol, $5 \%$ gum arabic (Sigma)) [29]. Gynoecia were then dissected and mounted on slides in Hoyer's solution, and examined on Axioscop2 microscope (Zeiss) with Nomarski optics. Ovule counts were made in chloral hydrate cleared stage 9-12 gynoecia. Estimations of outer integument defects and female gametophyte development were made from mature ovules or young seeds observed in stage 12 -14 flowers. Images were captured with a micropublisher 5.0 RTV digital camera and Q capture software (Q Imaging, Surrey, BC, Canada). Cropping and contrast adjustment of images was done in Adobe Photoshop CS2 (Adobe Software). Plant heights were measured manually when plants were at an equivalent developmental age as determined by the number of post-abscission siliques observed on the primary shoot. Statistical analysis was carried out in JMP7 (SAS Institute Incorporated) using ANOVA followed by pair wise comparisons with a Tukey-Kramer HSD test and an alpha value cutoff of 0.05 .

\section{Genotyping and T-DNA insertion site mapping}

The T-DNA insertion site was mapped for salk_056270 (cyp85A2-1) in At3g30180 within the end of exon 1 in the codon encoding glycine 45 . The asterisk (*) indicates the insertion site within the genomic DNA sequence: $5^{\prime}$ GCCAATATTTGGTGA*AACGACTGAGTTTCT3'). The T-DNA insertion site was mapped for salk_129352 (cyp85A2-2) within the end of exon 4 in the codon encoding glutamic acid 302 . The asterisk (*) indicates the insertion site within the genomic DNA sequence: 5'AGCTCT TGAAGAACT*CAGAGTATGTACTT3'.

Table 3 CYP85A2 mutant alleles described in this study

\begin{tabular}{llll}
\hline Allele & Other Designation & Allele Disruption & Reference \\
\hline cyp85A2-1 & salk_056270 & T-DNA insertion in CDS at amino acid 45 \\
\hline cyp85A2-2§ & salk_129352 & T-DNA insertion in CDS at amino acid 302 \\
\hline cyp85A2-4 & sum63 & uncharacterized rearrangement
\end{tabular}

$\S$ this allele (salk_129352) has been designated cyp85A2-2 by Nomura et al., 2005. The allele designated cyp85A2-2 in Kim et al., 2005 is a different allele (salk_068754) that was designated cyp85A2-3 by Nomura et al. 


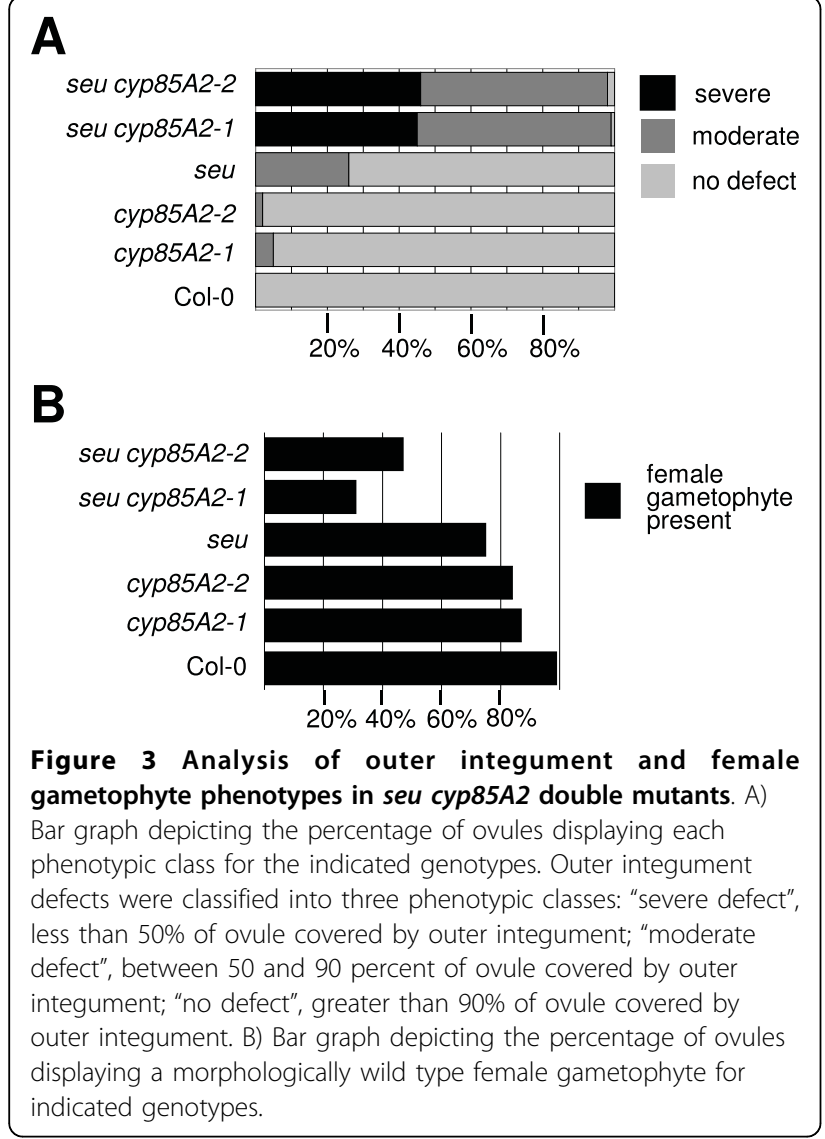

The oligonucleotide pairs: SALK_056270 LP (5' GAATTTCGTGCTGAAAATTGC3'), SALK_056270 RP (5'ACCCGAGATTCAGATTCAATG3'); and SALK_129 352 LP (5'CGTAAATTCTCCAACCTTT TGG3'), SALK_129352 RP (5'TTGTTGTGGGAACTCTATC GG3') were used with oligo LBb1 (5'GCGTGGA CCGCTTGCTGCAACT3') for genotyping and insertion site mapping.

\section{qRTPCR analysis}

For analysis of transcript abundance, inflorescences (inflorescence meristem through floral stage 12) were collected, frozen in liquid nitrogen and ground in

Table 4 qRT-PCR quantification of mean expression levels $s^{\S}$ of CYP85A2 and SEU transcripts in wt, seu and cyp85A2 mutants

\begin{tabular}{llll}
\hline & wt (Col-0) & seu-3 & cyp85A2-1 \\
\hline CYP85A2 & 0.29 & $0.12^{\mathrm{a}}$ & $0.12^{\mathrm{a}}$ \\
& $+/-0.03$ & $+/-0.01$ & $+/-0.02$ \\
\hline SEU & 0.43 & $0.12^{\mathrm{a}}$ & 0.39 \\
& $+/-0.02$ & $+/-0.01$ & $+/-0.05$ \\
\hline
\end{tabular}

${ }^{a}$ indicates statistically different from Col-0

(ANOVA and pair wise Tukey-Kramer HSD; alpha less than 0.05)

+/- indicates standard error of the mean

$\S$ Normalized to ADENOSINE PHOSPHORIBOSYL TRANSFERASE (AT1G27450) microcentrifuge tubes. RNA extraction, cDNA synthesis, and qRT-PCR were performed as previously described [8]. A single qRTPCR run contained four biological replicates, and each biological replicate was assayed in triplicate. Results shown in Table 4 are the mean expression of the indicated gene normalized to ADENOSINE PHOSPHORIBOSYL TRANSFERASE (At1g27450). Results are averages and standard error of the mean for four biological replicates. Statistical analysis of differences of means was carried out in JMP7 (SAS Institute Incorporated) using a Tukey-Kramer HSD test and a p value cutoff of 0.05 . Sequences of the oligonucleotides used for qRTPCR analysis: At3G30180-1440/1441F (5'GGAGGTGGAGTTAGGCTTTGCCC3') and At3G30180-1440/ 1441R - (5'TCTTCTCCATTCTCT TCCCATCTAT3')

\section{Mutagenesis}

Approximately 5,000 homozygous seu- 1 seeds were imbibed overnight in $4 \mathrm{mM}$ ethyl methane sulfonate in a $50 \mathrm{ml}$ conical tube. Seeds were then rinsed several times and planted to soil. Pools of M2 seeds were collected from approximately fifteen M1 plants. M2 pools were screened for enhanced gynoecial defects or female sterility.

\section{Mapping of sum63 mutation and sequencing of CYP85A2} genomic DNA from the sum63 mutant

Pollen from sum63 seu-1 double mutants (in the Ler background) was used to pollinate Col-0 plants. Resulting F2 plants were visually screened and genomic DNA was prepared from leaves of 53 plants that displayed the sum63 phenotype. The sum63 mutation was rough mapped between ciw11 and T32N15.42 on the third chromosome. We estimated the percentage recombination between the ciw 11 marker and the sum 63 mutation was $9.8 \%$ and between T32N15.42 and sum63 was 10.2\%. The oligonucleotide pairs AT3G30180-F1 and AT3G30180-613R as well as AT3G30180-445F and AT3G30180-1274R were used to amplify and sequence the first 1274 nucleotides (relative to transcriptional start site as position +1 ) of the CYP85A2 genomic DNA sequence from Ler and sum63 samples (See Table 2 for primer sequences). The oligonucleotide pair AT3G30180-2427F and AT3G30180-3UTR was successfully used to amplify and sequence the $3^{\prime}$-most portions. Several primer pairs expected to hybridize to the intervening portions of the CYP85A2 gene, as well as primer pairs that were expected to span the intervening region (i.e. AT3G30180-445F and AT3G30180-2938R) did not generate amplicons from the sum63 DNA while they did yield amplicons from the Ler DNA samples.

\section{List of abbreviations used}

SEUSS (SEU): seuss-modifier (sum); (CYP): cytochrome p450; (CS): castasterone; (BL): brassinolide; (Ler): Landsberg erecta; (Col): Columbia; (LUG): LEUNIG; (ANT): AINTEGUMENTA; 


\section{Authors' contributions}

SNW, EER, HB, and RGF all contributed to data collection and analysis. RGF devised the screen and wrote the paper. All authors have read and approved the final manuscript.

\section{Acknowledgements}

We thank the Arabidopsis Biological Research Center for seed stocks. We acknowledge Anna Stepanova for initially noting the phenotypic similarities between sum63 and published brassinosteroid pathway mutants. This work was supported by the National Science Foundation (grant no. IOS 0821896 to R.G.F.), the National Research Initiative of the U.S. Department of Agriculture (grant no. 2006-03378 to S.N.W.) and the U.S. Department of Agriculture, Agricultural Research Service (grant no. NC06759). H.B. was funded through a Research Experience for Undergraduates (REU) supplement to the NSF grant no. IOS0821896.

Received: 3 August 2010 Accepted: 13 September 2010 Published: 13 September 2010

\section{References}

1. Franks RG, Wang C, Levin JZ, Liu Z: SEUSS, a member of a novel family of plant regulatory proteins, represses floral homeotic gene expression with LEUNIG. Development 2002, 129(1):253-263.

2. Bao F, Azhakanandam S, Franks RG: SEUSS and SEUSS-LIKE transcriptional adaptors regulate floral and embryonic development in Arabidopsis. Plant Physiol 2010, 152(2):821-836

3. Sitaraman J, Bui M, Liu Z: LEUNIG_HOMOLOG and LEUNIG perform partially redundant functions during Arabidopsis embryo and floral development. Plant Physiol 2008, 147(2):672-681.

4. Sridhar W, Surendrarao A, Gonzalez D, Conlan RS, Liu Z: Transcriptional repression of target genes by LEUNIG and SEUSS, two interacting regulatory proteins for Arabidopsis flower development. PNAS 2004, 101(31):11494-11499.

5. Sridhar W, Surendrarao A, Liu Z: APETALA1 and SEPALLATA3 interact with SEUSS to mediate transcription repression during flower development. Development 2006, 133(16):3159-3166.

6. Gregis V, Sessa A, Colombo L, Kater MM: AGL24, SHORT VEGETATIVE PHASE, and APETALA1 redundantly control AGAMOUS during early stages of flower development in Arabidopsis. Plant Cell 2006, 18(6):1373-1382

7. Gonzalez D, Bowen AJ, Carroll TS, Conlan RS: The transcription corepressor LEUNIG interacts with the histone deacetylase HDA19 and mediator components MED14 (SWP) and CDK8 (HEN3) to repress transcription. Mol Cell Biol 2007, 27(15):5306-5315.

8. Azhakanandam S, Nole-Wilson S, Bao F, Franks RG: SEUSS and AINTEGUMENTA Mediate Patterning and Ovule Initiation during Gynoecium Medial Domain Development. Plant Physiol 2008, 146(3):1165-1181.

9. Liu Z, Franks RG, Klink VP: Regulation of gynoecium marginal tissue formation by LEUNIG and AINTEGUMENTA. Plant Cell 2000, 12(10):1879-1892.

10. Elliott RC, Betzner AS, Huttner E, Oakes MP, Tucker WQ, Gerentes D, Perez P, Smyth DR: AINTEGUMENTA, an APETALA2-like gene of Arabidopsis with pleiotropic roles in ovule development and floral organ growth. Plant Cell 1996, 8(2):155-168.

11. Klucher KM, Chow H, Reiser L, Fischer RL: The AINTEGUMENTA gene of Arabidopsis required for ovule and female gametophyte development is related to the floral homeotic gene APETALA2. Plant Cell 1996, 8(2):137-153.

12. Krizek BA: Ectopic expression of AINTEGUMENTA in Arabidopsis plants results in increased growth of floral organs. Dev Genet 1999, 25(3):224-236.

13. Mizukami Y, Fischer RL: Plant organ size control: AINTEGUMENTA regulates growth and cell numbers during organogenesis. Proc Natl Acad Sci USA 2000, 97(2):942-947.

14. Liu Z, Meyerowitz EM: LEUNIG regulates AGAMOUS expression in Arabidopsis flowers. Development 1995, 121(4):975-991.

15. Fujioka S, Yokota T: Biosynthesis and metabolism of brassinosteroids. Annu Rev Plant Biol 2003, 54:137-164

16. Clouse SD, Sasse JM: Brassinosteroids: Essential regulators of plant growth and development. Annu Rev Plant Phys 1998, 49:427-451.
17. Kim TW, Hwang JY, Kim YS, Joo SH, Chang SC, Lee JS, Takatsuto S, Kim SK Arabidopsis CYP85A2, a cytochrome P450, mediates the Baeyer-Villiger oxidation of castasterone to brassinolide in brassinosteroid biosynthesis. Plant Cell 2005, 17(8):2397-2412.

18. Nomura T, Kushiro T, Yokota T, Kamiya Y, Bishop GJ, Yamaguchi S: The last reaction producing brassinolide is catalyzed by cytochrome $\mathrm{P}-450 \mathrm{~s}$, CYP85A3 in tomato and CYP85A2 in Arabidopsis. J Biol Chem 2005, 280(18):17873-17879.

19. Clouse SD, Langford M, McMorris TC: A brassinosteroid-insensitive mutant in Arabidopsis thaliana exhibits multiple defects in growth and development. Plant Physiology 1996, 111(3):671-678.

20. Alonso JM, Stepanova AN, Leisse TJ, Kim CJ, Chen H, Shinn P Stevenson DK, Zimmerman J, Barajas P, Cheuk R, et al: Genome-wide insertional mutagenesis of Arabidopsis thaliana. Science 2003, 301(5633):653-657.

21. Smyth DR, Bowman JL, Meyerowitz EM: Early flower development in Arabidopsis. Plant Cell 1990, 2(8):755-767.

22. Pfluger J, Zambryski P: The role of SEUSS in auxin response and floral organ patterning. Development 2004, 131(19):4697-4707.

23. Nemhauser JL, Mockler TC, Chory J: Interdependency of brassinosteroid and auxin signaling in Arabidopsis. PLOS Biol 2004, 2(9):E258.

24. Hardtke CS: Transcriptional auxin-brassinosteroid crosstalk: who's talking? Bioessays 2007, 29(11):1115-1123.

25. Goda H, Sawa S, Asami T, Fujioka S, Shimada Y, Yoshida S: Comprehensive comparison of auxin-regulated and brassinosteroid-regulated genes in Arabidopsis. Plant Physiol 2004, 134(4):1555-1573.

26. Mouchel CF, Osmont KS, Hardtke CS: BRX mediates feedback between brassinosteroid levels and auxin signalling in root growth. Nature 2006, 443(7110):458-461

27. Bao F, Shen J, Brady SR, Muday GK, Asami T, Yang Z: Brassinosteroids interact with auxin to promote lateral root development in Arabidopsis. Plant Physiol 2004, 134(4):1624-1631

28. Nakamura A, Higuchi K, Goda H, Fujiwara MT, Sawa S, Koshiba T, Shimada Y, Yoshida S: Brassinolide induces IAA5, IAA19, and DR5, a synthetic auxin response element in Arabidopsis, implying a cross talk point of brassinosteroid and auxin signaling. Plant Physiol 2003, 133(4):1843-1853.

29. Berleth $T$, Jurgens $G$ : The role of the monopteros gene in organising the basal body region of the Arabidopsis embryo. Development 1993, 118(2):575-587.

doi:10.1186/1471-2229-10-198

Cite this article as: Nole-Wilson et al:: Synergistic disruptions in seuss cyp85A2 double mutants reveal a role for brassinolide synthesis during gynoecium and ovule development. BMC Plant Biology 2010 10:198.

\section{Submit your next manuscript to BioMed Central and take full advantage of:}

- Convenient online submission

- Thorough peer review

- No space constraints or color figure charges

- Immediate publication on acceptance

- Inclusion in PubMed, CAS, Scopus and Google Scholar

- Research which is freely available for redistribution 